\title{
Keep moving forward
}

\author{
Thomas A. D'Amico, MD
}

\author{
From the Division of Thoracic Surgery, Department of Surgery, Duke University Medical Center, Durham, NC. \\ Disclosures: Author has nothing to disclose with regard to commercial support. \\ Received for publication Nov 20, 2016; accepted for publication Nov 23, 2016; available ahead of print Jan 10, \\ 2017. \\ Address for reprints: Thomas A. D'Amico, MD, Division of General Thoracic Surgery, Duke University Medical \\ Center, DUMC Box 3496, Duke South, White Zone, Room 3589, Durham, NC 27710 (E-mail: thomas. \\ damico@duke.edu). \\ J Thorac Cardiovasc Surg 2017;153:1621-2 \\ $0022-5223 / \$ 36.00$ \\ Copyright (C) 2016 by The American Association for Thoracic Surgery \\ http://dx.doi.org/10.1016/j.jtcvs.2016.11.047
}

The application process for residency in thoracic surgery has changed with the advent of integrated (I-6) training programs. The editorial by Karim and Meyerson ${ }^{1}$ comprehensively reviews the issues that are relevant to the application process to these programs, from the perspective of the applicant and the program director. The senior author has a uniquely qualified point of view as an experienced Program Director in both General Surgery and Thoracic Surgery, and she is one of the leading Thoracic Surgery educators in the United States.

Many thoracic surgeons may be surprised to learn that general surgery program directors may discriminate against residents interested in thoracic surgery. However, I believe this point should be clarified: If this discrimination does exist at some general surgery programs, it is not new and would have been applied to residents interested in thoracic surgery and applying to general surgery for decades. Likewise, resident applicants interested in thoracic surgery have been generating 2 applications-one for programs for which thoracic surgery is acceptable and one for programs for which it may not be-for decades. Finally, this process does not double the work: It consists of changing a few words in the personal statement and substituting one recommendation.

Karim and Meyerson ${ }^{1}$ are to be commended for the survey of program directors and first year residents. It is disappointing that the response rate was so low, especially considering it was only a 6-question survey. Although the interview process may be overwhelming for the applicants (and the programs), I do not necessarily agree that the issues are unique to thoracic surgery. There are many small specialties with a high applicant to matched position ratio, and it is not uncommon for applicants to apply to multiple specialties under those conditions. It is fortunate that applicants who do not match in I-6 programs still have an opportunity to train in thoracic surgery, in Joint Training Programs or Traditional Programs.

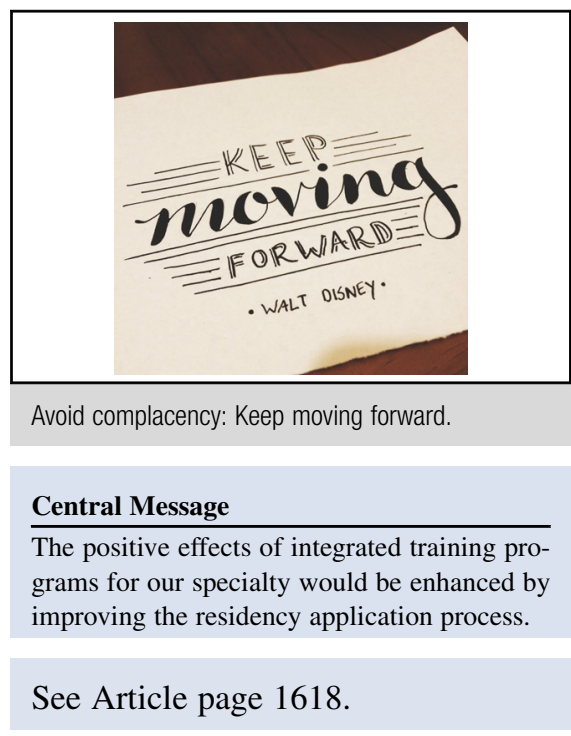

I agree that a comprehensive, transparent interview schedule could be published in advance of interviews (on the Thoracic Surgery Directors Association and Thoracic Surgery Residents Association Web sites), but this would not be helpful to the residents who need the most assistance-those who do not get many interviews and are in danger of not matching. However, it may guide applicants about how to budget their time and money in the interview months.

I would argue that it would be most beneficial to the applicants for programs to offer interviews on more than 1 or 2 dates and to consider giving interviews on different days of the week so there is less overlap of interview dates and more flexibility for applicants. Another benefit of this approach is that each interview date would have fewer applicants, allowing a more thorough evaluation process for both the applicants and the programs. Also, with more interview options, it would be more likely that applicants could interview at more programs in a region in 1 trip. Although this might interfere with the clinical flow in some programs, it seems to me that adding 1 or 2 more dates is not an untenable option.

The positive effect of these programs for our specialty would be enhanced by improving the application process, and we should avoid complacency and act soon. There are few efforts that are more important to a department, division, and program than the successful recruitment of the best residents. If follows 
that this process also has an important influence on the quality of care for all patients, both in the short term and the long term. The thoughtful analysis that the authors provide is an excellent platform for future discussions and debate regarding how to keep moving forward-to improve the residency application and training processes.

\section{Reference}

1. Karim AS, Meyerson SL. The residency application process: Challenges for our specialty? J Thorac Cardiovasac Surg. 2017;153:1618-20. 